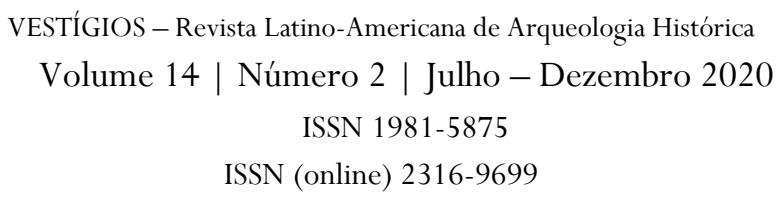

\title{
PROPOSTA DE DIAGNÓSTICO DE CONSERVAÇÃO PARA ACERVOS ARQUEOLÓGICOS - UM PROTOCOLO PARA A RESERVA TÉCNICA DO LACOR/UFPE
}

PROPUESTA DE DIAGNÓSTICO DE CONSERVACIÓN PARA COLECCIONES ARQUEOLÓGICAS - UN PROTOCOLO PARA EL DEPÓSITO LACOR/UFPE

CONSERVATION DIAGNOSIS PROPOSAL FOR ARCHAEOLOGICAL COLLECTIONS - A PROTOCOL FOR THE LACOR/UFPE STORAGE ROOM

Renata Libonati de Azevedo

Ana Catarina Peregrino Torres Ramos

Aliane Pereira de Oliveira

Amanda de Lima Costa Pestana

Henry Lavalle Sullasi

Matheus da Silva Araújo

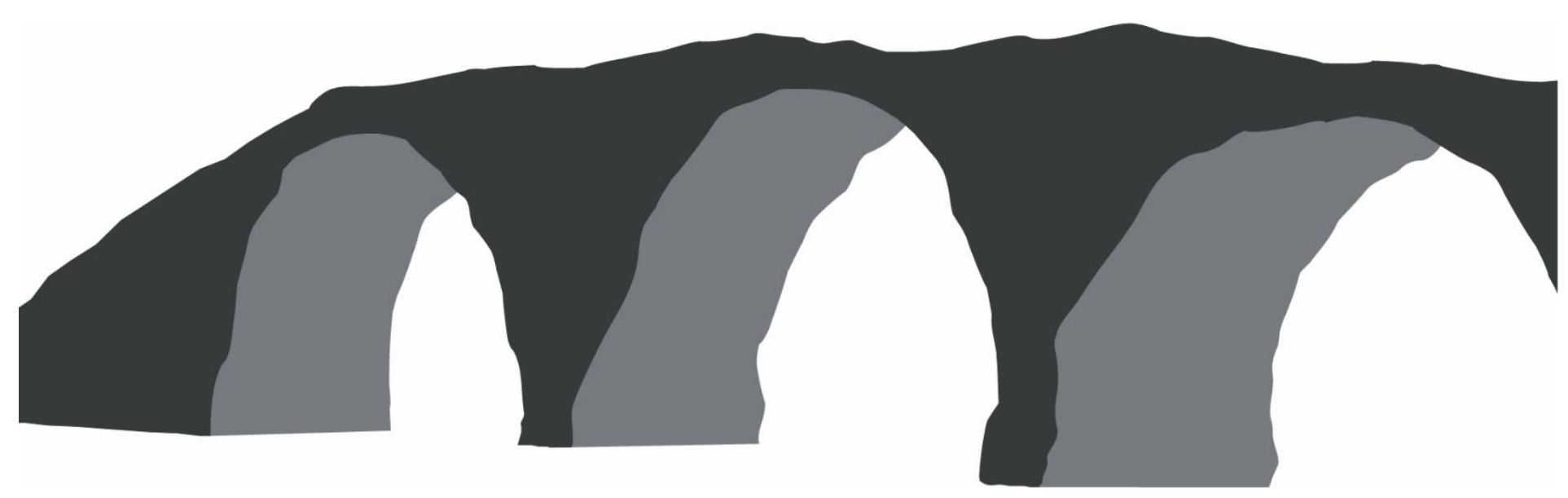




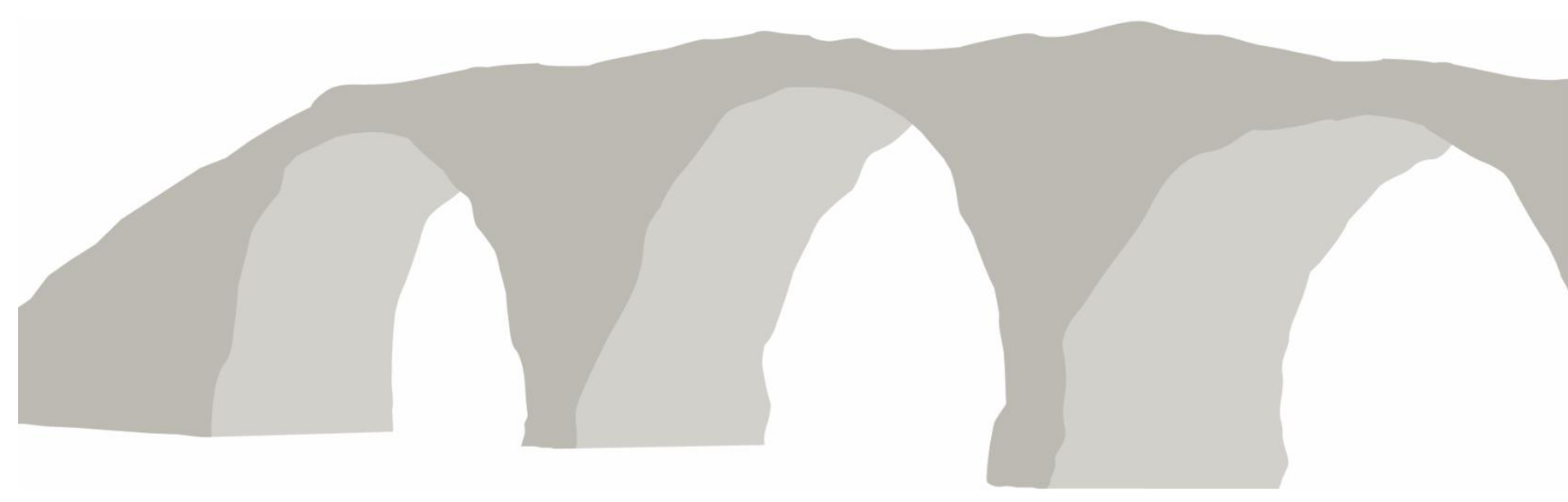

Submetido em 01 / 11 / 2020.

Revisado em: 09/12/2020.

Aceito em: 14/12/2020. 


\title{
PROPOSTA DE DIAGNÓSTICO DE CONSERVAÇÃO PARA ACERVOS ARQUEOLÓGICOS - UM PROTOCOLO PARA A RESERVA TÉCNICA DO LACOR/UFPE
}

\author{
PROPUESTA DE DIAGNÓSTICO DE CONSERVACIÓN PARA COLECCIONES \\ ARQUEOLÓGICAS - UN PROTOCOLO PARA EL DEPÓSITO LACOR/UFPE
}

\section{CONSERVATION DIAGNOSIS PROPOSAL FOR ARCHAEOLOGICAL COLLECTIONS - A PROTOCOL FOR THE LACOR/UFPE STORAGE ROOM}

\author{
Renata Libonati de Azevedo ${ }^{1}$, Ana Catarina Peregrino Torres Ramos², \\ Aliane Pereira de Oliveira ${ }^{3}$, Amanda de Lima Costa Pestana ${ }^{4}$, \\ Henry Lavalle Sullasi ${ }^{5}$, Matheus da Silva Araújo ${ }^{6}$
}

RESUMO

O acervo arqueológico sob responsabilidade de instituições de guarda e pesquisa deve ser preservado, uma vez que compõe o universo dos chamados bens patrimoniais. No Brasil, as recomendações para conservação de bens móveis estão a cargo da Portaria IPHAN nº196/2016. A partir de uma leitura minuciosa dessa portaria e diante da necessidade de avaliar o estado da conservação do acervo arqueológico existente na reserva técnica do Laboratório de Arqueologia para Conservação e Restauração do Departamento de Arqueologia da Universidade Federal de Pernambuco, foi criado o protocolo para diagnóstico de conservação que é apresentado neste trabalho. Esse protocolo foi baseado na Portaria IPHAN supracitada e vem sendo aplicado satisfatoriamente na referida reserva técnica. Em sua aplicação foi possível identificar os pontos relacionados à conservação do acervo que precisam ser modificados e aprimorados para uma conservação preventiva mais eficaz, não somente do acervo que está nessa reserva técnica, mas também em todas as outras

\footnotetext{
1 Doutora em Tecnologias Energéticas e Nucleares, Pesquisadora Colaboradora dos Laboratórios de Arqueologia para Conservação e Restauração (LACOR) e Laboratório de Estudos Arqueométricos (LEARQ), Universidade Federal de Pernambuco (UFPE), Departamento de Arqueologia, Centro de Filosofia e Ciências Humanas, 10 andar, CEP: 50.740-550 - Av. da Arquitetura, s/n, Cidade Universitária, Recife, Pernambuco, Brasil. E-mail: renata.libonati@ufpe.br. ORCID: https://orcid.org/0000-0003-4740-403X. ORCID: https://orcid.org/0000-0002-5929-3237.

${ }^{2}$ Doutora em Arqueologia, Professora, Coordenadora do LACOR, UFPE. E-mail: ana.tramos@ufpe.br. ORCID: https://orcid.org/0000$\underline{0002-8052-3674 .}$.

${ }^{3}$ Mestre em Antropologia, Técnica Administrativa em Educação, Arqueóloga do LACOR, UFPE. E-mail: aliane.oliveira@ufpe.br. ORCID: https://orcid.org/0000-0002-6888-4442.

${ }^{4}$ Graduanda em Arqueologia, Estagiária do LACOR. UFPE. E-mail: amanda.limacosta@,ufpe.br. ORCID: https://orcid.org/0000-00034894-6981.

${ }^{5}$ Doutor em Física, Professor, Coordenador do Programa de Pós-Graduação em Arqueologia da UFPE e do LEARQ.

E-mail: henry.lavalle@ufpe.br. ORCID: https://orcid.org/0000-0002-0690-6781.

${ }^{6}$ Arqueólogo, UFPE. E-mail: mjj.rem@gmail.com. ORCID: https://orcid.org/0000-0002-3634-314X.
} 
reservas do departamento. Além disso, esse protocolo pode servir como uma ferramenta para auxiliar outras instituições de guarda e pesquisa no diagnóstico de conservação de suas reservas.

Palavras-chave: conservação preventiva, acervos arqueológicos, reservas técnicas, protocolo de diagnóstico de conservação.

\section{RESUMEN}

El acervo arqueológico a cargo de las instituciones de custodia e investigación debe ser preservado, ya que forma parte del universo de los denominados bienes patrimoniales. En Brasil, las recomendaciones para la conservación de bienes muebles están a cargo de la Portaria IPHAN n¹96/2016. A partir de esta ordenanza, y dada la necesidad de evaluar el estado de conservación de la colección arqueológica en el depósito del Laboratório de Arqueologia para a Conservação e Restauração del Departamento de Arqueologia de la Universidade Federal de Pernambuco, se elaboró el protocolo de diagnóstico de conservación que se presenta en este trabajo. Este protocolo, con base en la mencionada ordenanza, y está siendo aplicado exitosamente en este depósito. En su aplicación fue posible identificar áreas que necesitan ser modificadas y mejoradas para tener una conservación más efectiva, no solo de la colección en este depósito, sino también en los demás depósitos de este departamento. Además, este protocolo puede servir como una herramienta para ayudar a otras instituciones de custodia y investigación a diagnosticar la situación de conservación de sus depósitos.

Palabras clave: conservación preventiva, colecciones arqueológicas, depósitos, protocolo de diagnóstico de conservación.

\section{ABSTRACT}

The archaeological collection under the responsibility of institutions of custody and research must be preserved since they constitute the universe of so-called heritage assets. In Brazil, the conservation recommendations for heritage assets are in the IPHAN ordinance $n^{\circ} 196 / 2016$. Through the meticulous reading of this ordinance, plus the necessity of checking the status of the conservation of the archaeological collection located in the storage room of the Laboratório de Arqueologia para Conservação e Restauração of the Departamento de Arqueologia, Universidade Federal de Pernambuco, a protocol was created for the conservation diagnosis that is presented in this work. This protocol, based on IPHAN ordinance above mentioned, has been applied satisfactorily in this storage room. During the use of this protocol, it was possible to identify the areas about conservation and care of collections that need to be modified and enhanced to have more effective conservation, not only for the collection that is in this storage room, but also other storage rooms of this department. Furthermore, this protocol could work as a tool to help other institutions of custody and research when carrying out the diagnosis of conservation of their storage rooms.

Keywords: preventive conservation, archaeological collections, storage rooms, protocol to conservation diagnosis. 


\section{INTRODUÇÃO}

O ser humano sempre foi um agente cultural ativo, imerso em redes sociais, intervindo e moldando os recursos naturais disponíveis conforme suas necessidades, construindo e produzindo objetos para fins específicos, em busca da sua perpetuação e da sua continuidade existencial ao transmitir, registrar e preservar os conhecimentos alcançados (Meskell, 2005; Carvalho, 2005). Portanto, cada monumento, cada objeto encontrado durante uma escavação arqueológica, independentemente do tempo e local em que foi produzido, é uma fonte única e rica em significação, informação e gera conhecimento (Ferrez, 1994), pois foi pensado e produzido para uma finalidade, seja utilitária, estética, ritualística etc., dentro de um contexto cultural e temporal, sendo, portanto, uma fonte rica de informações a respeito do povo que o produziu.

Enquanto intérprete desse testemunho cultural materializado, a ciência arqueológica não deve limitar-se apenas a escavar para descobrir novos bens e/ou a pesquisar para compreender aspectos da vida humana no passado a partir da cultura material resgatada. Para tal, a atuação do arqueólogo requer uma postura que integre de forma completa a pesquisa, a conservação e a socialização desses bens arqueológicos, ou seja, a gestão dos acervos se faz necessária.

Além de ser o que preconiza o IPHAN (2016), essa integração entre pesquisa, conservação e socialização por meio da gestão é a forma mais eficaz de aproximar os bens patrimoniais do cotidiano das gerações presentes e futuras. As dificuldades enfrentadas para tornar possível essa inserção social da comunidade ao conhecimento produzido através das pesquisas arqueológicas, bem como questões a respeito da necessidade de se democratizar o acesso ao público aos bens arqueológicos que se encontram nas reservas técnicas são tópicos que já foram abordados por Pereira (2017).

No tocante à conservação, a gestão dos acervos arqueológicos estabelece os procedimentos que devem ser adotados numa ação conjunta de todos os profissionais responsáveis pelo acervo. No âmbito do patrimônio cultural, a conservação configura-se como um conjunto de ações e estratégias que ampliam o tempo de vida dos bens patrimoniais. As informações produzidas, geridas e socializadas podem alcançar as comunidades gerando um processo de ressignificação, tão importante à sua preservação.

A gestão dos acervos arqueológicos e a disseminação da informação produzida, assim como a possibilidade de reanálise desta informação por parte das comunidades e pesquisadores interessados tanto do presente quanto do futuro, são partes importantes do processo de gestão de bens culturais, ao qual se liga a pesquisa arqueológica preventiva. (Caldarelli \& Cândido, 2017, p. 209)

Da relação entre conservação-degradação do acervo, que segundo Fernandéz (2013) foi percebida e estudada desde a década de 1950, é que surge a ideia da conservação preventiva, que desde então vem se consolidando como uma prática primordial e indispensável para retardar o desgaste e minimizar possíveis danos aos bens patrimoniais. Foi o Comitê Internacional de Conservação do Conselho Internacional de Museus, ICOM - CC, durante a $15^{\mathrm{a}}$ Conferência Trianual, em Nova Delhi, realizada no ano de 2008, que definiu o conceito de conservação como "as medidas e ações que tenham como objetivo a salvaguarda do patrimônio cultural tangível, assegurando sua acessibilidade para presentes e futuras gerações” (ABRACOR, 2010, p. 1).

Essas ações se dão principalmente através do controle ambiental do espaço em que o acervo é armazenado e do inventário, que consiste em uma base de dados em que todas as informações referentes a cada objeto do acervo estão contidas (Froner \& Souza, 2008a; Caldeira, 2006). Através da conservação preventiva, intervenções de natureza invasiva nos materiais arqueológicos podem ser minimizadas ou até mesmo evitadas, 
assegurando que todo o potencial de análise desse bem seja garantido, e que, assim, se cumpra seu papel dentro da pesquisa arqueológica, que é o de transmissão da história e memória a ele vinculadas (Ghetti, 2015). Como já ressaltado, essas medidas no âmbito da conservação preventiva estão dentro do escopo de ações da gestão de acervos, fundamentais para que qualquer instituição de salvaguarda do patrimônio arqueológico possa cumprir suas funções de pesquisa, conservação e extroversão.

Apesar de não haver dúvidas sobre a importância e necessidade da conservação preventiva para a salvaguarda de acervos arqueológicos de reservas técnicas, no contexto dos laboratórios de guarda e pesquisa ligados às universidades brasileiras, a exemplo do que verificamos na nossa instituição, é consenso que esse tipo de conservação seja um desafio (Sallés et al., 2017; Vasconcelos \& Alcântara, 2017; Ghetti, 2015; Milheira et al., 2015; Mesquita, 2012). Isso porque, num cenário em que há incorporações contínuas de grandes quantidades de objetos - decorrentes principalmente do aumento no número das pesquisas e da concessão de endosso institucional - associadas à uma limitação generalizada de recursos financeiros e de pessoal, reflexos diretos do atual momento político e econômico brasileiro, a gestão do acervo dessas instituições torna-se uma missão árdua.

Por estar ciente de seu papel na proteção e divulgação dos bens culturais do Brasil, garantindo assim o seu usufruto para as gerações presentes e futuras, o IPHAN, autarquia federal do Governo Brasileiro, atualmente vinculada ao Ministério do Turismo, publicou, em 2016, a Portaria n ${ }^{\circ} 196$, como uma forma de padronizar, orientar, monitorar e gerir as atividades de conservação do patrimônio arqueológico brasileiro. Nessa portaria, recomendações direcionadas aos coordenadores, pesquisadores e demais agentes envolvidos na pesquisa arqueológica versam, segundo seus critérios, sobre os requisitos mínimos que devem ser atendidos para a conservação dos bens arqueológicos móveis que estão em território brasileiro (IPHAN, 2016). Esses requisitos mínimos, elaborados sob a perspectiva da conservação preventiva, abordam fatores promotores de degradação e de ações preventivas quanto aos seguintes parâmetros: organização; edifício; sistemas auxiliares; reserva técnica; exposição, laboratório e atividades envolvidas; gestão do acervo; acondicionamento e mobiliário de guarda ou expositivo; bem como os cuidados gerais com o acervo.

Nos últimos anos, no processo de salvaguarda, o Departamento de Arqueologia da Universidade Federal de Pernambuco (UFPE), por meio de ações idealizadas pelo Laboratório de Arqueologia para Conservação e Restauração da Universidade Federal de Pernambuco (LACOR - UFPE) e desempenhadas por profissionais, estagiários e bolsistas dos demais laboratórios desse departamento, tem se dedicado a implantar melhorias em suas reservas técnicas adequando-as às recomendações existentes na legislação atual que regula o funcionamento das reservas técnicas arqueológicas, como a Portaria n¹96/2016 do IPHAN.

No intuito de contribuir para as discussões a respeito da gestão de acervos e compartilhar nossas experiências na adequação da reserva técnica localizada nas dependências do LACOR-UFPE à Portaria IPHAN 196/2016, este trabalho apresenta o Protocolo para Diagnóstico de Conservação (PDC).

A elaboração desse PDC é uma consequência dos esforços que estão sendo realizados na implementação de uma política de gestão para a conservação de acervos. Importante ressaltar que inicialmente esse protocolo foi aplicado apenas na reserva técnica situada no LACOR-UFPE, mas que posteriormente será expandido para todas as reservas técnicas sob a responsabilidade do Departamento de Arqueologia da UFPE. Partindo da premissa de que conhecimento é a base para qualquer ação eficaz, e levando em consideração a nossa experiência quanto ao uso desse protocolo, buscamos fornecer através dele um subsídio para a identificação 
dos problemas relacionados à conservação, permitindo a elaboração de estratégias mais efetivas de gestão no tocante a fatores de guarda, pesquisa e controle dos fatores de degradação em acervos arqueológicos.

\section{A CONSERVAÇÃO PREVENTIVA E A VIDA DOS OBJETOS}

Por diversas razões, ao longo do tempo, os objetos se degradam, seja pela natureza dos seus materiais constituintes, seja devido às condições ambientais a que estão sujeitos, pela utilização inadequada ou até mesmo por ações de vandalismo (Dias, 2018; Michalski, 2014). Escavações arqueológicas, por exemplo, são intervenções que iniciam processos degradantes que podem ser irreversíveis ao patrimônio. Ao serem removidos do contexto e ambiente ao qual estavam inseridos, um equilíbrio é rompido, e esses objetos passam a ser expostos a diversos fatores de risco promotores de degradação, como manuseio e transporte inadequado, por exemplo, que podem vir a causar um dano ou até mesmo a perda de um objeto. Portanto, toda atividade arqueológica precisa ser previamente planejada (pré e pós-escavação), visando minimizar ao máximo os possíveis danos aos objetos. Essas atividades podem ser entendidas como ações que abrangem aspectos de conservação, restauração e até mesmo de controle da deterioração natural dos objetos ao longo do tempo (Poccolo \& Tinoco, 2009). Essa visão é a base da conservação preventiva e tem sido defendida por diversos autores (Ghetti, 2015; Leal, 2014; Sallés \& Ribeiro, 2011; Froner, 1995; Lorêdo, 1994; Price, 1986).

A área da conservação preventiva se desenvolveu com o avanço científico interdisciplinar sobre o conhecimento dos processos de deterioração, com ações no material e no ambiente que o acondiciona. Segundo Fernandéz (2013), o termo Conservação Preventiva apareceu na década de 1950 e foi usado por um grupo de conservadores - restauradores anglo-saxões que identificaram em trabalhos publicados na década de 1930 os agentes de degradação que afetavam as coleções dos museus. Mas foi apenas na década de 1980 que de fato a conservação preventiva foi consolidada como área do conhecimento (Froner \& Souza,2008a). O histórico do desenvolvimento da conservação preventiva é descrito em trabalhos como o de Machado (2015), Carvalho \& Fritoli (2015), Froner \& Souza (2008a) e Caldeira (2006).

De uma forma geral, podemos sintetizar o pensamento da conservação preventiva, segundo as palavras de Guichen (2009, p. 40), como uma forma de mudar a mentalidade para que "o objeto de ontem se converta na coleção de hoje; a sala no edifício; o indivíduo na equipe; o presente no futuro; os profissionais no público; e no mais amplo sentido da palavra, o secreto na comunicação e o como no porquê".

Sendo assim, as reservas técnicas, ambientes destinados ao armazenamento do acervo arqueológico, precisam ser projetadas, planejadas, organizadas, monitoradas, e mantidas sob esta nova filosofia da conservação preventiva (Froner, 2008). Dentro dessa filosofia da conservação preventiva, os aspectos relacionados à degradação do acervo também precisam ser levados em consideração. Portanto, a identificação e estudo dos possíveis agentes de degradação e fatores de riscos associados aos acervos é indispensável para que ambientes favoráveis ao armazenamento adequado do acervo sejam construídos e mantidos (Deus, 2014; Froner \& Souza, 2008a).

Como pode ser observado na Tabela 1, diversos são os fatores de deterioração que podem afetar os acervos arqueológicos das reservas técnicas. Portanto, para a salvaguarda do acervo, é preciso que estes fatores de risco sejam evitados, ou pelo menos minimizados. Para que isso seja possível, um plano de gestão para a conservação do acervo deve ser traçado, visando, dentre vários aspectos, a definição de parâmetros mínimos para salvaguarda do acervo e das coleções arqueológicas (Ghetti, 2015). 
PROPOSTA DE DIAGNÓSTICO DE CONSERVAÇÃO PARA ACERVOS ARQUEOLÓGICOS UM PROTOCOLO PARA A RESERVA TÉCNICA DO LACOR/UFPE

Tabela 1. Fatores de risco associados a deterioração de acervos.

[Fonte: Adaptado de Deus (2014), apud Michalski (2004) e CCI (2002)].

\begin{tabular}{|c|c|c|c|}
\hline Fator de risco & Riscos associados & Prováveis causas & Gestão e controle \\
\hline $\begin{array}{l}\text { Forças físicas diretas } \\
\text { Ocasionadas por choques, } \\
\text { vibrações, abrasões e ação da } \\
\text { gravidade. }\end{array}$ & $\begin{array}{l}\text { Quebras; Distorções, } \\
\text { Perfurações; Arranhões; } \\
\text { Amassados. }\end{array}$ & $\begin{array}{l}\text { Terremotos; Guerras; } \\
\text { Manuseamento incorreto; } \\
\text { Reservas técnicas cheias; } \\
\text { Trânsito de peças; Obras; } \\
\text { Construções. }\end{array}$ & $\begin{array}{c}\text { Equipe treinada e preparada; } \\
\text { Planos de emergência. }\end{array}$ \\
\hline $\begin{array}{c}\text { Ladrões, vândalos e } \\
\text { pessoal distraído } \\
\text { Acesso não autorizado de } \\
\text { pessoas; estragos intencionais } \\
\text { (1) ou não intencionais (2). }\end{array}$ & $\begin{array}{l}\text { Principalmente objetos } \\
\text { populares e simbólicos. (1) } \\
\text { Perda total (salvo se } \\
\text { recuperado) (2) Perda ou } \\
\text { extravio. }\end{array}$ & $\begin{array}{l}\text { Criminosos profissionais e } \\
\text { amadores; Público em geral; } \\
\text { Equipe da instituição; objetos } \\
\text { altamente visados. }\end{array}$ & $\begin{array}{l}\text { Segurança; Gestão de } \\
\text { patrimônio; Expansão das } \\
\text { atividades curatoriais e de } \\
\text { pesquisa; Contato com a } \\
\text { polícia. }\end{array}$ \\
\hline $\begin{array}{c}\text { Fogo } \\
\text { Danos causado pela queima } \\
\text { do objeto. }\end{array}$ & $\begin{array}{l}\text { Destruição total, sem } \\
\text { recuperação; Abrasões; } \\
\text { Danos por fumaça; Danos } \\
\text { colaterais com água. }\end{array}$ & $\begin{array}{c}\text { Sistemas elétricos e } \\
\text { iluminação defeituosa; } \\
\text { Incêndio premeditado; } \\
\text { Fumo; Edifícios adjacentes. }\end{array}$ & $\begin{array}{l}\text { Segurança contra incêndio; } \\
\text { Equipe treinada; Plano para } \\
\text { incêndios }\end{array}$ \\
\hline $\begin{array}{c}\text { Água } \\
\text { Danos causados pela água. }\end{array}$ & $\begin{array}{l}\text { Marcas e eflorescência em } \\
\text { materiais porosos; Inchaço } \\
\text { de materiais orgânicos; } \\
\text { Corrosão metálica, Colas } \\
\text { dissolvidas. }\end{array}$ & $\begin{array}{l}\text { Infestações; Tempestades; } \\
\text { Telhados defeituosos; } \\
\text { Ligações de água e esgotos } \\
\text { defeituosos; Canalização dos } \\
\text { sistemas de supressão de } \\
\text { incêndios. }\end{array}$ & $\begin{array}{l}\text { Prevenção de emergência; } \\
\text { Equipe treinada; Serviço de } \\
\text { limpeza das instalações. }\end{array}$ \\
\hline $\begin{array}{c}\text { Pragas } \\
\text { Insetos, animais, fungos, } \\
\text { bactérias. }\end{array}$ & $\begin{array}{l}\text { Excreções danosas aos } \\
\text { materiais; Consumo de } \\
\text { materiais }\end{array}$ & $\begin{array}{l}\text { Paisagem circundante; Lixo; } \\
\text { Entrada de materiais de } \\
\text { construção; Circulação de } \\
\text { pessoas; Entrada de comidas } \\
\text { e materiais orgânicos; } \\
\text { Sujidades de fezes e urina. }\end{array}$ & $\begin{array}{c}\text { Equipe composta/auxílio de } \\
\text { biólogos; Empresas de } \\
\text { controle de pragas; Equipe } \\
\text { treinada; Serviços/espaços } \\
\text { de comida longe das } \\
\text { instituições. }\end{array}$ \\
\hline $\begin{array}{c}\text { Poluentes } \\
\text { Compostos que danificam os } \\
\text { objetos quando reagem com } \\
\text { seus materiais quimicamente. }\end{array}$ & $\begin{array}{l}\text { Poluentes transportados } \\
\text { pelo ar; Poluentes que se } \\
\text { transferem entre dois } \\
\text { materiais por um ponto de } \\
\text { contato; Poluente } \\
\text { intrínsecos ao material do } \\
\text { objeto. }\end{array}$ & $\begin{array}{c}\text { Edifício localizado em áreas } \\
\text { poluídas ou de grande } \\
\text { movimentação; Produtos } \\
\text { emissivos de poluentes. }\end{array}$ & $\begin{array}{l}\text { Áreas (expositivas e reservas } \\
\text { técnicas) protegidas dos } \\
\text { poluentes externos (distância } \\
\text { e uso de filtros); Objetos } \\
\text { acondicionados } \\
\text { corretamente; Limpeza } \\
\text { constante das áreas. }\end{array}$ \\
\hline $\begin{array}{c}\text { Luz } \\
\text { Agente danoso, porém, } \\
\text { necessário para visualizar } \\
\text { objetos. }\end{array}$ & $\begin{array}{l}\text { Objetos expostos } \\
\text { diretamente à luz natural ou } \\
\text { à luz artificial danosa. }\end{array}$ & $\begin{array}{l}\text { Radiações ultravioleta (UV) e } \\
\text { infravermelha (IR). }\end{array}$ & $\begin{array}{l}\text { Uso de filtros (UV e IR); } \\
\text { Evitar incidência direta da } \\
\text { luz solar. }\end{array}$ \\
\hline $\begin{array}{c}\text { Temperatura } \\
\text { Em níveis incorretos }\end{array}$ & $\begin{array}{c}\text { Temperaturas extremas } \\
\text { (altas ou baixas); Variações } \\
\text { bruscas. }\end{array}$ & $\begin{array}{c}\text { Incidência de luz; Transporte } \\
\text { de acervos; Climatização } \\
\text { insuficiente; Sistema de } \\
\text { controle de temperatura } \\
\text { defeituoso; Incêndios. }\end{array}$ & $\begin{array}{l}\text { Controle rígido e contínuo } \\
\text { da temperatura. }\end{array}$ \\
\hline $\begin{array}{l}\text { Umidade relativa } \\
\text { Em níveis incorretos }\end{array}$ & $\begin{array}{l}\text { Umidades extremas (altas } \\
\text { ou baixas); Variações } \\
\text { bruscas. Está ligado a } \\
\text { infestações por pragas }\end{array}$ & $\begin{array}{l}\text { Enchentes, vazamentos; } \\
\text { Transporte de acervos; } \\
\text { Climatização insuficiente; } \\
\text { controle de umidade relativa } \\
\text { defeituoso. }\end{array}$ & $\begin{array}{c}\text { Controle rígido e contínuo } \\
\text { da umidade relativa. }\end{array}$ \\
\hline $\begin{array}{c}\text { Dissociação } \\
\text { Agente de degradação que } \\
\text { afeta aspectos legais, } \\
\text { intelectuais ou culturais de } \\
\text { um determinado acervo. }\end{array}$ & $\begin{array}{c}\text { Perda de dados e } \\
\text { informações referentes ao } \\
\text { acervo. }\end{array}$ & $\begin{array}{l}\text { Sistemas de dados com falhas } \\
\text { e problemas (comum); Falhas } \\
\text { humanas; Equipe sem acesso } \\
\text { as bases de dados da } \\
\text { instituição. }\end{array}$ & $\begin{array}{l}\text { Treinamentos da equipe; } \\
\text { Manutenção e atualização } \\
\text { das bases de dados e } \\
\text { programas usados; backups } \\
\text { periódicos; Desenvolver } \\
\text { programas facilitadores da } \\
\text { gestão do acervo. }\end{array}$ \\
\hline
\end{tabular}




\section{RECOMENDAÇÕES DO ANEXO I DA PORTARIA IPHAN No 196/2016 PARA MINIMIZAR FATORES DE RISCO EM ACERVOS ARQUEOLÓGICOS}

Diante dessa variedade de fatores de risco e agentes de degradação, a vulnerabilidade a qual o acervo está exposto precisa ser compreendida para ser minimizada e quem sabe até eliminada (Froner \& Souza, 2008b; Michalski, 2004). Vários esforços nesse sentido já foram realizados, a exemplo do trabalho de Souza, Rosado e Froner (2008), que elaboraram um “Roteiro de Avaliação e Diagnóstico em Conservação Preventiva”, e os manuais propostos por instituições internacionais de referência na área de conservação, a exemplo do "Como Gerir um Museu: Manual Prático”, do Conselho Internacional de Museus em parceria com a Organização das Nações Unidas para a Educação, a Ciência e a Cultura (ICOM-UNESCO, 2004); do "Roteiro Prático de Parâmetros para a Conservação de Acervos", do Conselho para Museus, Livrarias e Arquivos (MLA), traduzido por Santos \& Souza (2004); e do "Conservation Assessment: a proposed model for evaluating museum environmental management needs", do Instituto de Conservação Getty (GCI, 1999).

Em comum, esses esforços visam o estabelecimento de diretrizes e recomendações para potencializar o desenvolvimento de soluções sustentáveis e apropriadas para a solução dos mais diversos problemas no âmbito da conservação dos acervos, servindo de guias para todas as instituições de guarda e pesquisa, incluindo as brasileiras.

A priori, a Portaria IPHAN nº196/2016 definiu um marco legal no âmbito da conservação preventiva para as instituições de guarda e pesquisa brasileiras, uma vez que esta tem força de lei e até então não havia um documento regulatório oficial definindo tais diretrizes e recomendações para essas instituições, que dentro de suas experiências, vivências, necessidades e realidades distintas, as elaboravam de diferentes formas. Contudo, é importante salientar que a leitura detalhada dessa portaria para a construção do protocolo aqui apresentado nos mostrou alguns pontos críticos que precisam ser discutidos e repensados junto à comunidade interessada.

No que tange às instituições de guarda e pesquisa, o Anexo I da Portaria IPHAN nº196/2016 define uma série de recomendações que foram divididas em áreas estratégicas, a saber: organização; edifício/prédio; sistemas auxiliares; reservas técnicas; exposição; gestão do acervo; acondicionamento; e por fim os aspectos gerais. Essas áreas estratégicas já foram amplamente trabalhadas nos manuais internacionais de diagnóstico de conservação, a exemplo do GCI (1999) e do roteiro proposto por Souza et al. (2008). Como já mencionado, o importante é que esse anexo da portaria IPHAN permite essa padronização das recomendações mínimas para a conservação de bens móveis, servindo de subsídio para o planejamento, evitando ou minimizando futuras deteriorações ou perdas dos acervos e coleções. Essas recomendações são direcionadas a questões estratégicas como o registro, armazenamento, manipulação, embalagem, transporte e controle das condições ambientais.

Em relação à organização, essa portaria elenca vários aspectos que envolvem a segurança do espaço e do acervo, como seguro contra sinistros de roubo e incêndio, plano de evacuação e questões sobre demanda de espaço físico para oferecimento de endosso institucional. Espaços distintos para laboratório com área limpa e suja, reservas técnicas e extroversão são incentivados, minimizando ou evitando acidentes e contaminação dos objetos do acervo. Outra importante recomendação presente nesse documento no tocante à área organizacional, que já havia sido discutida previamente por Froner \& Souza (2008a), se refere à necessidade de se ter uma equipe interdisciplinar fixa ou oriunda de intercâmbios com pesquisadores colaboradores, os quais podem contribuir com a inserção da perspectiva de sua disciplina para as demandas existentes. Dessa forma, a gestão dos acervos arqueológicos sob a guarda dessas instituições torna-se mais eficiente, evitando-se, por 
exemplo, que as reservas técnicas guardem uma quantidade de acervo além do seu espaço disponível para um armazenamento adequado.

Em relação aos edifícios e seus sistemas auxiliares, as recomendações elencadas alertam quanto aos cuidados necessários à construção e manutenção do espaço em que a reserva se encontra. Desta forma, fatores promotores de deterioração do acervo, que estão presentes no ambiente externo, podem ser controlados. Preocupações com o risco de incêndio, controle da umidade relativa e temperatura, bem como controle de pragas, devem ser constantes. Segundo Michalski (2004; 2013) e Strang \& Kigawa (2013), quando a umidade relativa e a temperatura estão em níveis extremos, ou com grandes variações, elas atuam como agentes promotores de mudanças dimensionais, de reações químicas e de deterioração biológica nos objetos. Portanto, a preocupação com esses fatores e a adoção de medidas de correção e controle é fundamental para potencializar a segurança e conservação do acervo, desacelerando sua degradação. Nesse sentido, Gonçalves, Souza \& Froner (2008) também reforçam a importância e a necessidade das instituições possuírem equipe multidisciplinar para a elaboração dos projetos de edificação.

No que se refere ao uso das reservas técnicas, o Anexo I da Portaria IPHAN nº 196/2016 aborda questões relacionadas ao controle de fatores ambientais, dimensão espacial, segurança em relação à circulação de pessoas, bem como avaliação de riscos sobre o local onde o edifício está instalado. Uma dessas questões, por exemplo, trata do fato de que as reservas técnicas devem ser ambientes exclusivos para a guarda de acervos, ou seja, um ambiente de fluxo extremamente controlado. Em trabalhos como o de Froner (2008), essas questões já haviam sido pontuadas e discutidas.

Os pontos referentes à exposição, ao laboratório e às atividades desenvolvidas apresentados no mesmo documento tratam sobre uma questão que é muito preocupante e que já vem sido debatida há algum tempo em trabalhos como o de Caldarelli \& Candido (2017) e Pereira (2017): fazer com que o acervo arqueológico circule, seja através do incentivo à realização de pesquisas, seja através de ações de extroversão arqueológica. Ou seja, as instituições não devem limitar-se à guarda e conservação dos acervos, precisam torná-los visíveis para a comunidade.

Em relação à gestão do acervo, seguindo a linha de pensamento defendida em trabalhos como o do ICOM (2014), Monteiro (2014) e Matos (2012), o documento aqui referenciado, enfatiza a necessidade de se implantar protocolos e sistemas de gerenciamento de informações que permitam manter uma base de dados contendo todas as informações sobre um objeto, desde a sua catalogação até eventuais intervenções, sinistros e movimentações internas e externas à reserva técnica. $\mathrm{O}$ "Manual de gestão da reserva técnica sob a salvaguarda do LEPAARQ - UFPEL" (Milheira et al., 2017) é um exemplo claro da importância da gestão e do gerenciamento de informações para a conservação dos acervos, uma vez que a instituição de guarda passa a ter total conhecimento sobre o status de cada material que compõe o acervo, contribuindo para a proteção desse patrimônio.

As questões que dizem respeito ao acondicionamento, armazenamento, mobiliário e cuidados gerais com os acervos arqueológicos são relevantes porque apresentam elementos básicos para evitar que os materiais que os compõem sofram danos. É importante salientar que isso, junto aos demais fatores humanos e à própria degradação dos materiais que depois de serem tirados de seus ambientes originais podem se desestabilizar e se tornar mais frágeis e sensíveis, exige por parte das instituições cuidados específicos para evitar danos por choques, contaminações e demais interações químicas, microclimas, perda de informações, entre outros. 
Diante disso, assim como em outros trabalhos (Froner, 2008; Souza et al., 2008), o Anexo I da Portaria IPHAN n¹96/2016 não poderia deixar de abordar este tópico. Por exemplo, um dos pontos tratados se refere ao mobiliário utilizado, que deve oferecer proteção quanto aos danos físicos, químicos e biológicos, bem como serem firmes, seguros e feitos de materiais quimicamente estáveis. Segundo a portaria, uma ação necessária é a vistoria periódica das reservas técnicas e de setores que contenham acervo, visando monitorar seu estado de conservação.

\section{Proposta de Protocolo para Diagnóstico de ConservaÇão (PDC) BASEADO NO ANEXO I DA PORTARIA IPHAN No196/2016}

A conservação está inserida dentro das atividades e ações que envolvem a gestão dos acervos e atua no sentido de buscar identificar as vulnerabilidades às quais os acervos estão expostos, permitindo, assim, que a integridade dos objetos seja mantida o mais próximo possível da sua condição original. De acordo com Froner \& Souza (2008a), "Conhecimento é poder! E este poder é um aliado em ações administrativas, gerenciais e organizacionais que visem a melhora das condições das coleções”. Portanto, conhecimento é peça-chave e indispensável para uma efetiva conservação e consequentemente gestão do acervo, sendo o diagnóstico do estado de conservação uma boa maneira de se conhecer a real situação desse acervo.

A importância do diagnóstico de conservação frente às ações de gestão do acervo, os roteiros de avaliação abordando os principais aspectos para uma efetiva conservação do acervo, além de sugestões de modelos para realizar o diagnóstico de conservação podem ser encontrados em publicações tanto no âmbito nacional (Machado, 2015; Souza et al., 2008) quanto no internacional (IBERMUSEUS-ICCROM, 2018; Dawson, 2011 ; Camacho, 2007; ICOM-UNESCO, 2004; GCI, 1999; HCC, 1999).

Independentemente do tipo de instituição, aspectos abordados e acervo para o qual foi desenvolvido, o roteiro do modelo de diagnóstico de conservação irá auxiliar na compreensão da organização como um todo, possibilitando identificar as áreas de maior risco para o acervo. Desta forma, é possível planejar ajustes e melhorias que permitirão um melhor controle ambiental e dos sistemas de acondicionamento do acervo. Além disso, trata-se de uma ferramenta adaptável e flexível às necessidades e condições institucionais, que deve ser aplicada com o intuito de se implementar uma política de preservação (Souza et al., 2008).

Com o advento da Portaria IPHAN n¹96/2016, que trouxe em seu Anexo I as "Recomendações para a Conservação de Bens Arqueológicos Móveis” específicas para as instituições de guarda e pesquisa, a equipe do LACOR-UFPE decidiu elaborar à luz desses parâmetros um Protocolo para Diagnóstico de Conservação (PDC), pois era preciso saber se, enquanto Instituição de Guarda e Pesquisa, o Departamento de Arqueologia da Universidade Federal de Pernambuco estava descumprindo alguma dessas recomendações. Nesse sentido, a proposta de PDC apresentada na Tabela 2 foi pensada e elaborada no intuito de servir como ferramenta para diagnosticar, de forma prática e rápida, o estado de conservação do acervo, as condições físicas e organizacionais da infraestrutura, visando auxiliar no processo de elaboração do plano de conservação do Departamento de Arqueologia da UFPE enquanto Instituição de Guarda e Pesquisa.

Como pode ser observado na Tabela 2, os fatores e cuidados considerados no PDC estão baseados nas recomendações do Anexo I da Portaria IPHAN n¹96/ 2016, referentes à conservação de bens móveis, destinadas às instituições de guarda e pesquisa, e foram agrupados pelos mesmos níveis de atuação propostos na referida portaria, a saber: Organização; Edifício/prédio; Sistemas auxiliares; Reservas técnicas; Exposição; Gestão do Acervo; Acondicionamento; Aspectos Gerais. 
Tabela 2. Protocolo para Diagnóstico de Conservação (PDC) em acervos de instituições de guarda e pesquisa. Elaborado pelos autores (2020).

\begin{tabular}{|c|c|c|c|c|}
\hline \multirow{2}{*}{ Nível } & \multirow{2}{*}{ Fatores e Cuidados } & \multicolumn{2}{|c|}{ Possui? } & \multirow{2}{*}{$\begin{array}{c}\text { Observações e } \\
\text { comentários }\end{array}$} \\
\hline & & Sim & Não & \\
\hline \multirow{7}{*}{ 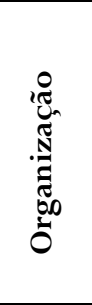 } & Seguro contra roubo e incêndio & & & \\
\hline & Certificado do corpo de Bombeiros & & & \\
\hline & Plano de evacuação & & & \\
\hline & Área própria para laboratório & & & \\
\hline & Área própria para reserva técnica & & & \\
\hline & Área própria para exposições e extroversão & & & \\
\hline & Equipe interdisciplinar capacitada & & & \\
\hline \multirow{8}{*}{ 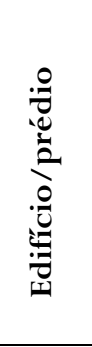 } & Localização salubre & & & \\
\hline & Localização em ambiente com alto nível de poluição & & & \\
\hline & Infiltrações e fissuras & & & \\
\hline & Isolamento térmico & & & \\
\hline & Uso de materiais não inflamáveis & & & \\
\hline & Tintas livres de ácidos e poluentes & & & \\
\hline & Piso resistente e antiaderente & & & \\
\hline & Possui sistemas auxiliares & & & \\
\hline \multirow{15}{*}{ 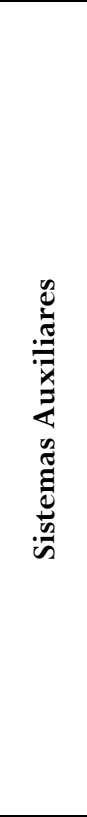 } & Extintor de incêndio & & & \\
\hline & Detector de fumaça & & & \\
\hline & Iluminação de emergência & & & \\
\hline & Sinalizador de saída & & & \\
\hline & Alarmes & & & \\
\hline & Cercas elétricas & & & \\
\hline & Câmeras de segurança & & & \\
\hline & Vigilantes & & & \\
\hline & $\begin{array}{l}\text { Sistema de climatização ambiental para manutenção estável da } \\
\text { temperatura e umidade. } \\
\text { (Ex.: ar-condicionado e desumidificador) }\end{array}$ & & & \\
\hline & Medidores de umidade e temperatura & & & \\
\hline & Sistema hidráulico & & & \\
\hline & Iluminação indireta e uso de lâmpadas de LED. & & & \\
\hline & Filtros de poluentes & & & \\
\hline & Revisão profissional & & & \\
\hline & $\begin{array}{l}\text { Revisão e controle dos sistemas auxiliares realizado por } \\
\text { profissionais especializados (Ex. eletricistas, encanadores, } \\
\text { engenheiros, arquitetos etc.) }\end{array}$ & & & \\
\hline \multirow{9}{*}{ 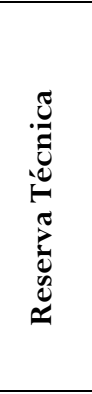 } & Uso exclusivo para guarda de acervo & & & \\
\hline & Limpeza & & & \\
\hline & Ambiente de fácil acesso e circulação & & & \\
\hline & Capacidade compatível com o acervo & & & \\
\hline & Ambiente vedado & & & \\
\hline & Pontos de água e ralos & & & \\
\hline & Cestos de lixo & & & \\
\hline & Apenas uma porta de acesso & & & \\
\hline & Acesso apenas a pessoas autorizadas & & & \\
\hline \multirow{6}{*}{ 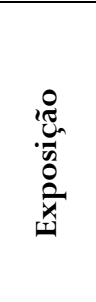 } & Incentivo a divulgação do acervo (práticas de extroversão) & & & \\
\hline & Registro de visitação & & & \\
\hline & Atividades de conservação preventiva & & & \\
\hline & Área limpa para manuseio do acervo & & & \\
\hline & Controle de empréstimo entre acervos. & & & \\
\hline & $\begin{array}{l}\text { Equipe multidisciplinar e capacitada, com treinamento específico } \\
\text { para pessoas com necessidades especiais. }\end{array}$ & & & \\
\hline
\end{tabular}




\begin{tabular}{|c|c|c|c|}
\hline Nível & Fatores e Cuidados & Possui? & $\begin{array}{l}\text { Observações e } \\
\text { comentários }\end{array}$ \\
\hline \multirow{6}{*}{ 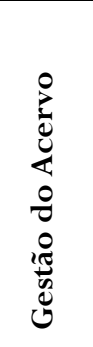 } & Política contendo os protocolos de gestão & & \\
\hline & Normas de empréstimo e recebimento de acervos & & \\
\hline & Plano de evacuação do acervo & & \\
\hline & Inventário atualizado & & \\
\hline & Sistema de base de dados atualizado e informatizado & & \\
\hline & $\begin{array}{l}\text { Checagem e contagem periódica do acervo para identificação de } \\
\text { possíveis danos ao acervo bem como identificar ações de } \\
\text { vandalismo, extravios, furtos. }\end{array}$ & & \\
\hline \multirow{9}{*}{ 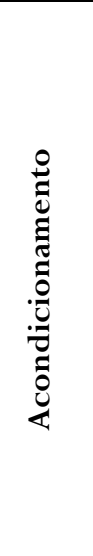 } & $\begin{array}{l}\text { Sistema de acondicionamento que facilita a localização, } \\
\text { identificação e manuseio dos objetos }\end{array}$ & & \\
\hline & $\begin{array}{l}\text { Armazenamento realizado de forma segura com proteção contra } \\
\text { danos físicos, químicos e biológicos. }\end{array}$ & & \\
\hline & Isolamento entre acervo e mobiliário. & & \\
\hline & $\begin{array}{l}\text { Afastamento do mobiliário (entre as paredes e o mobiliário: } \\
10 \mathrm{~cm} \text {; entre o chão e o acervo: } 15 \mathrm{~cm} \text { ) }\end{array}$ & & \\
\hline & $\begin{array}{l}\text { Acervo organizado, sem caixas empilhadas e sobrepesos nas } \\
\text { caixas. }\end{array}$ & & \\
\hline & Sistemas de amortecimento de choques & & \\
\hline & Suportes para manuseio & & \\
\hline & Acervo acondicionado por tipologias & & \\
\hline & Manutenção de etiquetas e invólucros & & \\
\hline \multirow{6}{*}{ 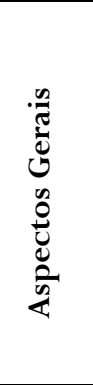 } & Produtos químicos armazenados em local específico e seguro. & & \\
\hline & Descarte correto dos produtos químicos & & \\
\hline & $\begin{array}{l}\text { Ambiente limpo e protegido contra infestações de insetos e } \\
\text { animais }\end{array}$ & & \\
\hline & Ambiente favorável a conservação do acervo & & \\
\hline & $\begin{array}{l}\text { Treinamento técnico da equipe para ações de limpeza, } \\
\text { conservação e identificação de danos }\end{array}$ & & \\
\hline & $\begin{array}{l}\text { Periodicamente, as práticas adotadas e a infraestrutura que } \\
\text { guarda o acervo são revistas, buscando-se melhorias. }\end{array}$ & & \\
\hline
\end{tabular}

Em relação à estrutura do PDC, apresentado na Tabela 2, dentre os diversos formatos possíveis para a elaboração de um protocolo, optamos pelo formato de planilha pela facilidade que apresenta. A ideia de utilizar respostas objetivas do tipo "sim” ou "não" para realizar o diagnóstico surgiu com as leituras das Planilhas de Trabalhos do RE-ORG (IBERMUSEUS-ICCROM, 2018), no trabalho de Machado (2015) e nas listas de autoverificação proposta por Dawson (2011). A escolha dessa metodologia se deve ao fato de sua praticidade e capacidade organizacional possibilitando uma visão integral do acervo em suas mínimas características. Um espaço para observações e comentários também foi incluído para que informações relevantes que surgissem durante a execução do PDC pudessem ser registradas.

Para a execução do PDC, recomendamos que uma equipe interdisciplinar esteja envolvida e que uma vez identificados os problemas, essa equipe possa, em conjunto, desenvolver soluções práticas, eficientes e sustentáveis para o acervo.

\section{A EXPERIÊNCIA DO LACOR - A RETEC-ARQ/UFPE}

O Laboratório de Arqueologia para Conservação e Restauro (LACOR) (Figura 1), criado em 2013, é um dos laboratórios de pesquisa do Departamento de Arqueologia da Universidade Federal de Pernambuco (DARQ/UFPE). No entanto, a pesquisa arqueológica na UFPE, começou há quase 40 anos, com os trabalhos realizados por arqueólogos lotados no Departamento de História da referida instituição. Com a criação do 
Curso de Bacharelado e do Departamento de Arqueologia, em 2009, o acervo existente foi incorporado e hoje encontra-se sob a guarda desse departamento.

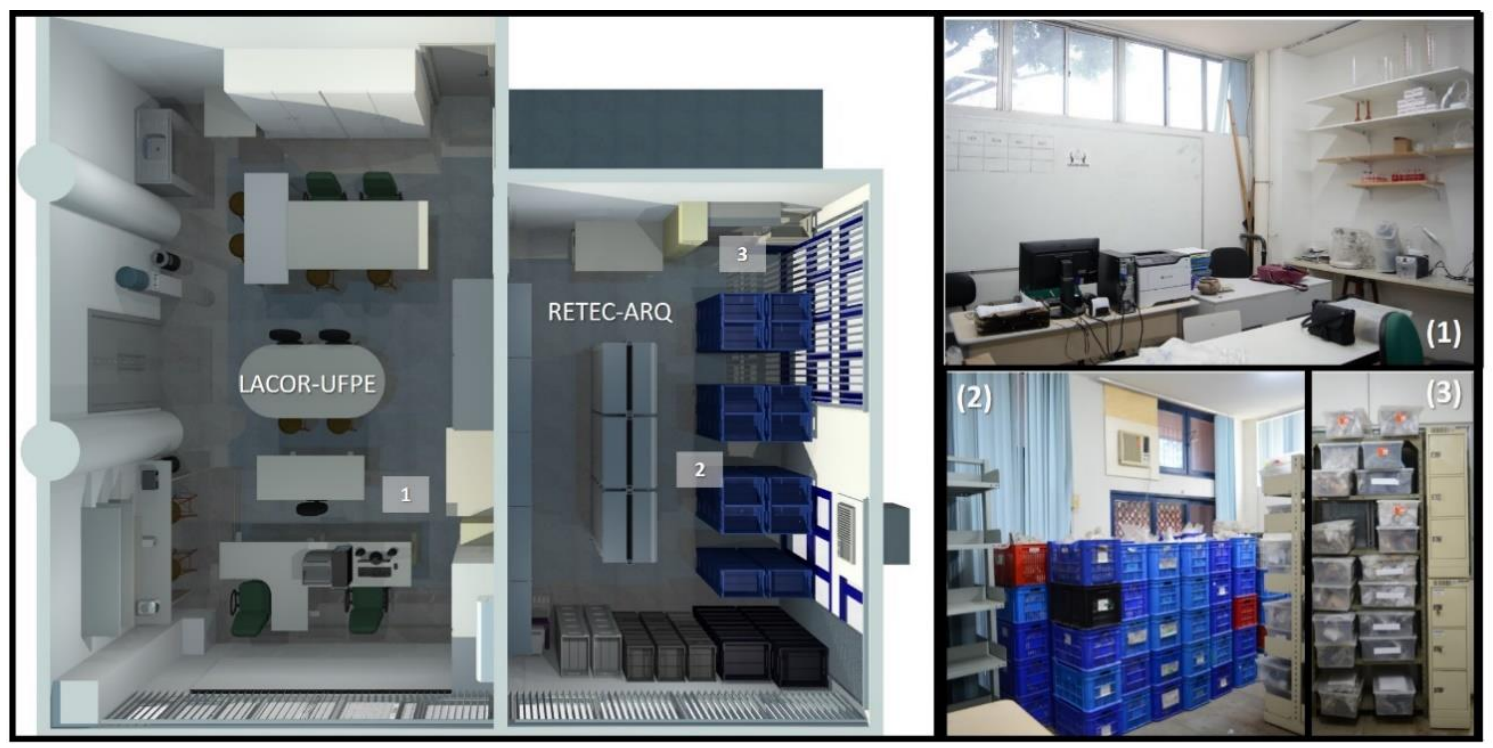

Figura 1. Modelo 3D e fotos dos espaços referentes ao LACOR-UFPE e RETEC-ARQ: (1) Foto de parte da sala do LACORUFPE; (2) e (3) Fotos mostrando os detalhes da RETEC-ARQ/UFPE. Elaborado pelos autores (2020) com imagens gentilmente cedidas por Ravena Barbosa Machado de Souza (2020), mestranda do Programa de Pós-Graduação em Arqueologia da UFPE.

Nesse contexto, esse acervo arqueológico engloba um conjunto de objetos provenientes de diversos sítios arqueológicos pré-históricos e históricos do estado de Pernambuco e de outros estados do Nordeste, pesquisados ao longo de todos esses anos, até os dias de hoje. A maior parte do acervo foi reunida a partir de pesquisas acadêmicas no campo da arqueologia através de prospecções e escavações arqueológicas realizadas, além do acervo proveniente de projetos de arqueologia preventiva a partir do fornecimento de endosso institucional. Há também uma parcela menor proveniente de doações de terceiros. Esse acervo, atualmente estimado em mais de duzentos mil objetos, é composto pelos mais diversos tipos de materiais (Figura 2) e está distribuído em cinco reservas técnicas, dentre as quais a RETEC-ARQ/UFPE situada no LACOR-UFPE. É importante salientar que essa divisão do acervo entre todas essas reservas técnicas, se dá por conta das dificuldades de obtenção de uma área única para manter todo o acervo, uma vez que partilhamos o prédio com outros departamentos, que também têm suas demandas por espaço.

Como pode ser observado na Figura 2, desses milhares de objetos que formam o acervo geral do Departamento de Arqueologia da UFPE, quase metade (47\%) é composto por materiais do tipo cerâmico (fragmentos, vasilhas, cachimbos etc.). Ossos humanos e de animais (11\%), materiais líticos (10\%), metais (9\%), sobretudo ferro, e vidros ( $8 \%)$ também são frequentes. Além desses materiais, outros tipos de materiais (15\%) também estão presentes, a saber: sedimentos, garrafas de grés, quartzo, ocre, porcelanas, louças, azulejos, ladrilhos, telhas, tijolos, argamassas, madeira, dentes, sementes, carvões, fibras vegetais, coprólitos e materiais malacológicos. 


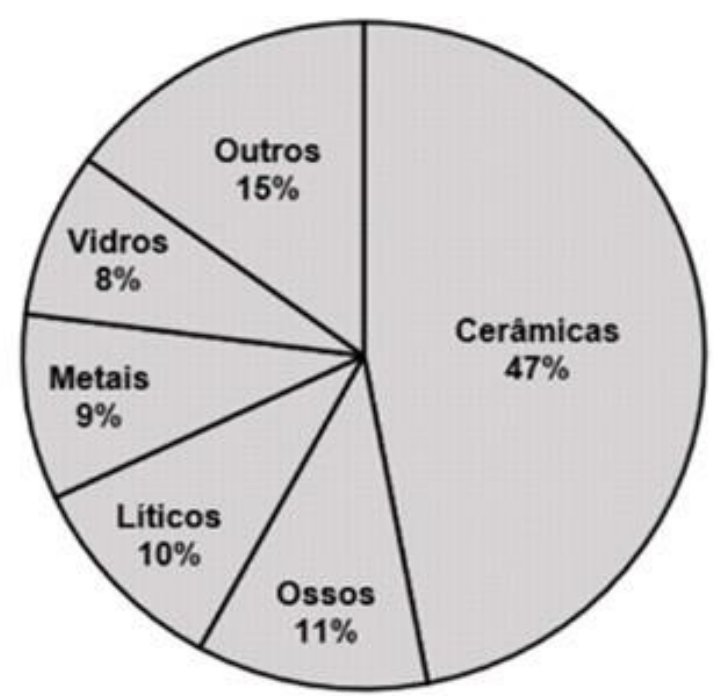

Figura 2. Distribuição percentual dos tipos de materiais que compõem o acervo arqueológico do DARQUEO/UFPE. Outros refere-se a: sedimentos, garrafas de grés, quartzo, ocre, porcelanas, louças, azulejos, ladrilhos, telhas, tijolos, argamassas, madeira, dentes, sementes, carvões, fibras vegetais, coprólitos, materiais malacológicos. Os valores apresentados estão baseados numa estimativa preliminar quantitativa do acervo. Elaborado pelos autores (2020).

Nos últimos anos, a incorporação de novos objetos tem sido frequente, o que tem gerado um aumento no volume do acervo, que não é acompanhado por uma ampliação do espaço físico disponível da reserva. Diante da publicação da portaria IPHAN nº196/2016, as inquietações sobre a efetividade das ações empregadas para a conservação do acervo ganharam força, surgindo questionamentos sobre como poderíamos melhorar o ambiente das reservas, sob o ponto de vista da conservação preventiva.

Como ponto de partida, a forma encontrada para responder tais questionamentos foi através de um diagnóstico da conservação do acervo da reserva situada no LACOR/UFPE, através da concepção e aplicação do Protocolo para Diagnóstico de Conservação apresentado neste trabalho. Após a realização desse diagnóstico, constatamos que alguns dos mecanismos existentes para garantir uma melhor qualidade da conservação do acervo arqueológico existente precisavam ser incrementados para atender o máximo possível às exigências da Portaria nº196/2016 do IPHAN, ou seja, ainda precisamos direcionar nossas ações na tentativa de solucionar as deficiências identificadas, o que é um desafio diante da realidade financeira da nossa instituição que não é diferente de outras instituições públicas de guarda de material arqueológico.

Do ponto de vista organizacional, o LACOR-UFPE cumpre boa parte dos requisitos. Como pode ser observado na Figura 1, o laboratório e a reserva técnica encontram-se em espaços distintos. Além disso, ele conta também com áreas para extroversão em outros espaços dentro do domínio do Departamento de Arqueologia da UFPE. Possui uma equipe fixa composta por uma arqueóloga como coordenadora, um físico especializado em análises físico-químicas de material arqueológico como vice coordenador, uma arqueóloga de laboratório e um técnico em conservação e restauro. Além disso, o laboratório conta com a contribuição temporária de outros pesquisadores de diferentes áreas, assegurando a interdisciplinaridade requerida para um efetivo cuidado com o acervo existente. Diante desse quadro de profissionais, apesar das dificuldades comuns às instituições de guarda brasileiras, contamos com um corpo técnico interdisciplinar diversificado, embora haja ainda a urgente necessidade de contratação de profissionais de nível superior nas áreas de conservação e museologia.

Em relação à certificação em segurança contra incêndios, os espaços do laboratório e da reserva possuem dispositivos de combate ao fogo como extintores de diversos tipos e classes. O projeto contra incêndio e 
consequente plano de evacuação do prédio, essencial em casos de sinistros por incêndio está em fase de reestruturação. Há uma rota de fuga delimitada que atualmente está parcialmente comprometida pelo fechamento de uma das vias de acesso ao prédio. Como essa reserva técnica está localizada dentro das dependências da UFPE, especificamente do Centro de Filosofia e Ciências Humanas ( $\mathrm{CFCH}$ ) da UFPE, a certificação em segurança contra incêndios precisa ser solicitada por meios institucionais mais amplos, e não diretamente pelo laboratório, uma vez que ela se refere ao prédio inteiro e não somente ao presente laboratório e sua reserva.

A UFPE promoveu a capacitação de funcionários do $\mathrm{CFCH}$ para a formação de uma brigada de incêndio no ano de 2014, com o objetivo de capacitar os profissionais pertencentes ao quadro de servidores desse centro para atuar na prevenção e combate ao princípio de incêndio, bem como na evacuação da área e primeiros socorros em caso de sinistro, até a chegada do Corpo de Bombeiros. Dentre os profissionais que receberam o treinamento, estão três membros do Departamento de Arqueologia, inclusive a arqueóloga do LACOR/UFPE. Os cortes de verba dos anos subsequentes impediram que os brigadistas recebessem os cursos de reciclagem anual necessários para rememorar os procedimentos práticos e conceitos operacionais envolvidos na atuação da brigada de incêndio.

A RETEC-ARQ/UFPE está localizada no primeiro andar do prédio do CFCH/UFPE. Um prédio de 15 andares construído na década de 1960 localizado numa área rodeada de estacionamentos, lanchonetes e restaurantes, com grande fluxo de pessoas e comércio. Sazonalmente, alguns pontos de infiltração ocorrem nesse prédio e isso, infelizmente, também já ocorreu na área da RETEC-ARQ/UFPE. Por isso, diariamente a equipe vistoria a sala no intuito de identificar possíveis pontos de infiltração. Se por ventura isso ocorre, o setor de manutenção da UFPE é imediatamente acionado. A equipe tem trabalhado em busca de uma solução definitiva para o problema junto a esse setor.

Alguns sistemas auxiliares não estão presentes, como por exemplo, o do isolamento térmico. Para tanto, é preciso recursos financeiros dos quais o laboratório não dispõe no momento. Contudo, apesar da RETECARQ/UFPE se localizar em uma área que não foi originalmente projetada para abrigá-la, ela possui muitos dos requisitos necessários para a conservação, tais como: piso resistente e antiaderente, paredes pintadas com tintas livres de ácidos e poluentes, cortinas e janelas que evitam incidência direta da luz no acervo.

O controle da temperatura e umidade relativa tem sido realizado através de medições com termohigrômetros, registradas de forma manual em um livro registro, duas vezes ao dia (manhã e tarde), nos dias de funcionamento do laboratório. Mesmo estando situada em uma região úmida e quente (a temperatura média anual da cidade do Recife gira em torno dos $25-26^{\circ} \mathrm{C}$, com umidade relativa acima dos $70 \%$ ), o uso de aparelhos de ar-condicionado, mesmo que desligados durante a noite e fins de semana por exigências internas do setor de infraestrutura do CFCH/UFPE, bem como o uso de desumidificadores, tem permitido que o ambiente da RETEC-ARQ/UFPE permaneça dentro dos valores considerados ideais para a conservação do acervo, sem variações bruscas de temperatura e umidade relativa na maior parte do tempo.

Alguns dos sistemas auxiliares ainda não compõem essa reserva técnica. Detectores de fumaça, alarmes e câmeras de segurança, que existiam há até alguns anos atrás, estão desativados e necessitando de reestruturação ao longo de todo o prédio do $\mathrm{CFCH}$. A segurança do prédio é realizada por vigilantes e pela polícia do campus universitário. Apenas membros efetivos da equipe da referida reserva técnica têm acesso às chaves do laboratório e da reserva técnica, bem como há uma grade de ferro na porta que dá acesso ao laboratório. Extintores de incêndio estão disponíveis e são compatíveis com a natureza material do acervo. 
Em relação à RETEC-ARQ/UFPE, as recomendações são atendidas basicamente tendo como ponto crítico a dimensão do espaço físico, que já se encontra insuficiente para abrigar o acervo. Nesse sentido, está em andamento, um projeto para transferir o acervo do LACOR-UFPE para um novo local, maior, contando com uma área destinada para atividades de extroversão, a ser projetada conforme as orientações do IPHAN. Para tanto, é preciso conseguir recursos financeiros, um desafio que ainda precisa ser vencido.

No tocante à exposição, as recomendações requeridas pela Portaria IPHAN n¹96/2016 são parcialmente atendidas, uma vez que são utilizadas vitrines expositivas em outros laboratórios do Departamento de Arqueologia da UFPE, com a ocorrência de eventos para a exposição de partes selecionadas do acervo, contudo, essas ações ainda ocorrem de forma muito tímida e pontual. Levando em conta que essa portaria estabelece que as reservas técnicas sejam espaços exclusivos para a guarda de acervos e que sua entrada seja exclusiva de pessoas autorizadas, bem como que a permanência e trânsito sejam evitados, percebemos que ela regulamenta as reservas técnicas do tipo tradicional, mas não ampara a criação de espaços visitáveis nas reservas técnicas, mesmo que para sua implantação sejam adotadas dimensões e serviços adequados à visitação, com elementos que garantam a segurança do acervo, como o controle de acesso e mobiliário adequado e seguro, requisitos básicos para a criação desses espaços, conforme estabelece Delavenay (2012).

Na nossa experiência, pensamos que é imprescindível uma atualização da Portaria IPHAN nº196/2016 para que se dê amparo legal às reservas arqueológicas visitáveis, que podem funcionar como um espaço para a extroversão do conhecimento arqueológico, estabelecendo os parâmetros básicos para o seu funcionamento. Viabilizar formas alternativas de espaços para extroversão arqueológica é promover a inclusão de instituições que não contam com um espaço específico em que se possa desenvolver essas atividades, como um museu, por exemplo.

Entendemos que os parâmetros estabelecidos pela Portaria IPHAN nº196/2016 em relação a esse ponto são uma medida que visa a segurança dos acervos, mas ao mesmo tempo isso consolida a ideia da reserva técnica como um ambiente privado, aprofundando o distanciamento entre o conhecimento produzido a partir das pesquisas arqueológicas e a sociedade como um todo. Essa é uma situação que reflete o pensamento de Wichers (2014), que diz que os materiais arqueológicos são exumados, passam a compor o que chamamos de "bens da União" e, de repente, sua manipulação é restrita aos especialistas, aos acadêmicos, ao invés de seguir o movimento das mudanças teórico-metodológicas do escopo da Museologia, que consiste em democratizar não apenas o acesso, mas também a seleção e produção do patrimônio cultural.

Em relação às atividades de conservação preventiva, tem ocorrido uma crescente busca em efetivá-las nos últimos anos, não apenas no LACOR-UFPE, mas no departamento como um todo. De uma forma integrada e multidisciplinar, através de seus docentes, discentes, corpo técnico e colaboradores de outras áreas, como físicos, químicos e biólogos, tem-se buscado conhecer cada vez mais os objetos ali presentes, como forma de mantê-los vivos e potencialmente informativos. Alguns trabalhos no âmbito da conservação preventiva de acervos já foram realizados. Dentre estes, podemos citar a proposta de Ghetti (2015) para a elaboração de um plano de gestão integrada para a conservação dos acervos arqueológicos; e os trabalhos de conclusão de curso de Santos (2017), Huther (2018) e Marques (2019), que buscaram, respectivamente, uma forma mais adequada de realizar o acondicionamento de remanescentes ósseos, entender os processos de degradação dos artefatos de natureza férrica presentes em nossas reservas técnicas, e mostrar o potencial do acervo para a elaboração de coleções de referência.

No que se refere à gestão, o grande desafio tem sido conferir e atualizar o inventário e a base de dados. Além do grande volume do acervo, muitas das peças nele encontradas precedem à criação dos laboratórios e 
reservas técnicas e, sobretudo, a adoção dos ideais da filosofia da conservação preventiva. Atualmente, tanto a equipe do LACOR-UFPE quanto as dos outros laboratórios e núcleos de pesquisa estão unindo esforços nesse sentido. A ideia é que na base de dados, além do número de identificação e procedência, também, constem informações a respeito do estado de conservação das amostras e eventuais processos de restaurações. Este trabalho faz parte dessas atividades que estão sendo realizadas para a elaboração de uma política de gestão de acervos do Departamento de Arqueologia da UFPE.

Em relação ao acondicionamento do acervo, a reserva técnica em questão cumpre as recomendações apontadas, exceto na organização, visto que algumas caixas ainda estão empilhadas sobre outras devido à questão do espaço, como pode ser observado na Figura 1. Essa não é uma questão tão crítica porque essas caixas são adequadas para empilhamento, contudo a equipe envolvida na gestão da reserva técnica tem pensado em ações como a aquisição de novas estantes e distribuição dos materiais em caixas de menor dimensão, que, inclusive, permitirão que menos materiais sejam reunidos em cada caixa, de modo a contribuir ainda mais com sua conservação, uma vez que diminui o risco de choque e atrito.

Os produtos químicos são guardados em áreas próprias e o seu descarte é realizado de forma adequada, através de uma política de descarte de resíduos implantada pela própria UFPE. A capacitação técnica de profissionais integrantes do LACOR-UFPE tem sido realizada na busca de uma melhor capacitação da equipe para lidar com o acervo de forma mais eficaz.

Dentre todas as inquietações que surgiram durante a aplicação do protocolo, com tantos itens a serem cumpridos, tantos detalhes, pensamos como as instituições de guarda de pequeno porte poderiam atender aos parâmetros solicitados na portaria. Diante da carência de instituições de guarda no Brasil, o problema de lotação das reservas técnicas como um todo, bem como o fato de que a própria legislação voltada para os bens arqueológicos preconiza que os materiais arqueológicos resgatados nas atividades, sejam elas acadêmicas sejam de arqueologia preventiva, permaneçam na mesma unidade da federação em que foram encontrados, se faz urgente pensar caminhos que garantam a sobrevivência dessas instituições de guarda de pequeno porte. Nesse panorama, há a necessidade de se discutir alternativas para fazer uma gestão de acervos apropriada e eficaz para a proteção do acervo arqueológico com recursos limitados. Essa questão é de extrema importância quando pensamos na socialização do conhecimento produzido através das pesquisas arqueológicas, a democratização do acesso e o diálogo com as comunidades.

Diante de tantas demandas a serem atendidas e dos desafios que permeiam a gestão e conservação dos acervos arqueológicos, temos consciência da necessidade da implantação de políticas públicas que fortaleçam as instituições de guarda e pesquisa brasileiras. Apesar de todas as dificuldades elencadas para alcançar de forma plena as recomendações da Portaria IPHAN nº196/2016, acreditamos que as ideias aqui apresentadas possam servir de subsídio para uma melhor prática de preservação do patrimônio arqueológico.

\section{CONSIDERAÇÕES FINAIS}

As reservas técnicas são espaços destinados à salvaguarda de acervos arqueológicos que precisam ser preservados para as gerações futuras. Para que isso seja possível, a conservação preventiva precisa ser empregada através do atendimento aos requisitos básicos de infraestrutura e gestão. No Brasil, as recomendações para conservação de bens arqueológicos móveis estão preconizadas na Portaria IPHAN no196/2016. 
Buscando aproximar o gerenciamento da RETEC-ARQ/UFPE com as normas brasileiras para a conservação do acervo arqueológico da referida portaria, foi criado pela equipe do LACOR-UFPE o Protocolo para o Diagnóstico de Conservação (PDC) apresentado neste trabalho, adotando a reserva técnica situada nesse laboratório como projeto-piloto para sua aplicação. Portanto, o PDC aqui proposto surge do entendimento de que uma gestão efetiva dos acervos se faz necessária para a consolidação da conservação preventiva como elemento primordial para promover a prevenção e o controle da deterioração dos acervos, bem como para produzir conhecimento para subsidiar ações de extroversão do patrimônio arqueológico, ou seja, exercendo a função social que se espera da arqueologia e, ao mesmo tempo, atendendo as prerrogativas legais para as instituições de guarda de material arqueológico.

O protocolo foi construído com base no Anexo I da Portaria IPHAN n¹96/2016 que reconhecemos como um importante instrumento de regulação para as instituições de guarda, apesar de sabermos que, quando aplicado à realidade de instituições públicas como a nossa, existem dificuldades para o cumprimento de algumas de suas recomendações, devido a problemas como limitações de recursos financeiros e de infraestrutura, além da carência de equipe interdisciplinar, que são questões comumente enfrentadas quando se depende de recursos governamentais para continuar em funcionamento. Para as instituições de guarda, a tarefa de se "manter vivas", após os sucessivos cortes e enxugamento de recursos financeiros dos últimos anos, não tem sido fácil de se transpor.

Enquanto elemento que permite um diagnóstico da situação de uma instituição de guarda em relação aos parâmetros exigidos pela Portaria IPHAN nº196/2016, o PDC proposto mostra-se uma ferramenta útil para o planejamento de atividades futuras que envolvem a gestão do acervo arqueológico sob a responsabilidade das instituições de guarda brasileiras.

O protocolo foi aplicado na RETEC-ARQ/UFPE, resultando em um diagnóstico que possibilitou verificar o quanto as práticas de gestão e infraestrutura adotadas pelo LACOR-UFPE em relação à RETEC-ARQ/UFPE estavam próximas, ou não, das recomendações da Portaria IPHAN nº196/2016. Ou seja, a partir desse diagnóstico pode-se reconhecer as áreas que precisam ser aprimoradas, bem como pensar em estratégias para tornar mais eficazes as práticas de conservação preventiva para esse acervo.

O PDC nos mostrou fragilidades em relação a diversos pontos, como a necessidade de maior atenção a ser dada a algumas categorias do acervo, como o metálico, que já vem sendo alvo de pesquisas; a questão da segurança contra incêndio, que precisa ser aprimorada; o equilíbrio do isolamento e controle térmico; e principalmente a questão do espaço, que necessita de ampliação frente às demandas contínuas e crescentes da pesquisa arqueológica e da concessão de endosso institucional pelo Departamento de Arqueologia da UFPE.

Entendemos que embora tenhamos atendido minimamente a grande parte dos elementos requeridos pela portaria, ainda será preciso realizar investimentos de natureza financeira e pessoal para alcançar de forma plena os parâmetros estabelecidos. Esse é, portanto, ainda um desafio a ser enfrentado.

O mais importante é que, a partir da experiência aqui relatada, o PDC apresentado possa ser usado como ferramenta estratégica para a realização do diagnóstico de conservação de acervos das demais reservas técnicas do Departamento de Arqueologia da UFPE, fundamentando o planejamento de atividades futuras para o acervo arqueológico sob a responsabilidade desse departamento. A aplicação sucessiva desse protocolo dará também subsídios para que possamos ampliar e ajustar o próprio protocolo, identificar suas potencialidades e pontos críticos para que possamos avaliar de forma mais precisa e detalhada a situação das reservas técnicas e do seu acervo. Também se espera que este documento sirva com uma ferramenta para outras instituições de guarda e 
pesquisa para realização do diagnóstico de conservação de suas reservas, auxiliando em suas atividades estratégicas de salvaguarda do patrimônio arqueológico.

\section{REFERÊNCIAS BIBLIOGRÁFICAS}

A Heritage Collections Council, HCC. (1999). Development of a best practice model for conservation and preservation assessment plans for cultural collections - V1: Final Project Report: Methodology and Analysis. Em colaboração com ArtLab Australia, History Trust of South Australia e State Library of New South Wales. Retrieved from: https://aiccm.org.au/wpcontent/uploads/2020/01/best practice vol1 1.pdf.

Associação Brasileira dos Conservadores - Restauradores, ABRACOR. (2010). Terminologia para definir a conservação do Patrimônio cultural tangível. Tradução ao português da Resolução adotada pelos membros do ICOM-CC durante a XV Conferência Trianual, Nova Delhi, 22-26 de setembro de 2008. Boletim Eletrônico da Associação Brasileira dos Conservadores-restauradores (ABRACOR). Rio de Janeiro, n. 1.

Caldeira, C. C. (2006). Conservação preventiva: histórico. Revista CPC, 1(1). p.91-102.

Camacho, C. (Org.). (2007). Plano de Conservação Preventiva: Bases orientadoras, normas e procedimentos. Lisboa: Instituto dos Museus e da Conservação Palácio Nacional da Ajuda. Retrieved from: http://www.patrimoniocultural.gov.pt/static/data/ljf/ipmplanoconservacaopreventiva.pdf.

Carvalho, S. K. P. (2005). Conservação Preventiva: Análise de condições ambientais em espaços museológicos por meio de um método de previsão. (master’s thesis). Centro Federal de Educação Tecnológica do Paraná, Paraná, Brasil.

Carvalho, S. K. P. \& Fritoli, C. L. (2015). Conservação de bens culturais: Nas Trilhas do Patrimônio Cultural (Vol. 5). Brasília: Universidade de Brasília - Faculdade de Ciência da Informação.

Dawson, A. (Org.). (2011). Benchmarks in Collection Care 2.0: A Self-Assessement Checklist. Reino Unido: Mla. Retrieved from: https://collectionstrust.org.uk/wpcontent/uploads/2016/08/Benchmarks2 updated Oct 2014-3.compressed.pdf.

Delavenay, A. H. (2012). De almacén a centro de conservación de colecciones. Almacenes de museos. Espacios internos, propuestas para su organización. Revista del Comité Español de ICOM, 3, p.8-15.

Deus, N. B. C. (2014). Análise de conservação preventiva na exposição em trânsito O Império em Brasília - 190 Anos da Assembleia Constituinte de 1823. (undergraduate thesis). Universidade de Brasília, Brasília, Brasil.

Dias, M. P. (2018). Curadoria e conservação arqueológica no Rio Grande do Sul: um levantamento de métodos. (master's thesis). Universidade de São Paulo, São Paulo, Brasil.

Fernandéz, I. M. G. (2013). Historia de la Conservación Preventiva-Parte I. Ge-Conservación, 5. p. 27- 41.

Ferrez, H. D. (1994). Documentação Museológica: Teoria para uma boa Prática. Cadernos de Ensaio: Estudos de Museologia, 2. p. 64-74.

Froner, Y-A. (1995). Conservação preventiva e patrimônio arqueológico e etnográfico: ética, conceitos e critérios. Revista Do Museu de Arqueologia e Etnologia, 5, p. 291-301.

Froner, Y-A. (2008). Tópicos em Conservação Preventiva 8: Reserva Técnica. Belo Horizonte: LACICOR-EBAUFMG, IPHAN.

Froner, Y-A. \& Souza, L. A. C. S. (2008a). Tópicos em Conservação Preventiva 3: Preservação de bens patrimoniais: conceitos e critérios. Belo Horizonte: LACICOR-EBA-UFMG, IPHAN.

Froner, Y-A. \& Souza, L. A. C. S. (2008b). Tópicos em Conservação Preventiva 7: Controle de pragas. Belo Horizonte: LACICOR-EBA-UFMG, IPHAN. 
Getty Conservation Institute, GCI. (1999). The Conservation Assessment: a proposed model for evaluating museum environmental management needs. EUA: Getty Conservation Institute.

Ghetti, N. C. (2015). Saber cuidar: a conservação arqueológica na perspectiva da preservação, salvaguarda e valorização do acervo arqueológico. Cuadernos del Instituto Nacional de Antropología y Pensamiento Latinoamericano - Series Especiales, 2(3). p. 54-70.

Gonçalves, W. B., Souza, L. A. C. \& Froner, Y-A. (2008). Tópicos em Conservação Preventiva 6: Edifícios que abrigam coleções. Belo Horizonte, LACICOR-EBA-UFMG, IPHAN.

Guichen, G. (2009). Medio siglo de Conservación Preventiva. (interview). Retrieved from: http://www.geiic.com/ojs/index.php/revista/article/viewFile/62/pdf.

Huther, A. F. M. (2018). Conservação de artefatos ferrosos em acervo técnico: O caso do laboratório de arqueologia da UFPE. (undergraduate thesis). Universidade Federal de Pernambuco, Brasil.

Ibermuseus, ICCROM. (2018). RE-ORG: Um Método para Reorganizar a Reserva Técnica de Museus. II. Planilhas de Trabalho. Versão em português, Brasil.

Conselho Internacional de Museus e Organização das Nações Unidas para a Educação, a Ciência e a Cultura, ICOM/UNESCO. (2004). Como Gerir um Museu: Manual Prático. Boylan, P. J. (Org.). França: Franly S.A. Retrieved from: https:// www.sisemsp.org.br/blog/wp-content/uploads/2012/09/Manual-Comogerir-um-museu-ICOM-Unesco.pdf

Instituto do Patrimônio Histórico e Artístico Nacional, IPHAN. (2016). Portaria Iphan de 18 de maio de 2016. Retrieved from: http://pesquisa.in.gov.br/imprensa/jsp/visualiza/idex.jsp?data=23/05/2016\&jornal= 1 \&pagina $=84 \&$ total Arquivos $=192$.

Leal, A. P. R. (2014). Arqueologia, museologia e conservação: documentação e gerenciamento de coleções provenientes do Sítio Bárbara (Pelotas - RS). (master's thesis). Universidade Federal de Pelotas, Pelotas, Brasil.

Lorêdo, W. M. (1994). Manual de Conservação em Arqueologia de Campo. Rio de Janeiro. Brasil: Instituto do Patrimônio Cultural. Departamento de Proteção.

Machado, B. P. (2015). A importância do diagnóstico de conservação para nortear as ações de preservação em arquivos, bibliotecas e museus. (undergraduate thesis). Faculdade de Ciência da Informação, Brasília, Brasil.

Marques, C. M. (2019). Proposta de extroversão da reserva técnica do Departamento de Arqueologia da UFPE: A difusão das louças para as instituições de ensino. (undergraduate thesis). Universidade Federal de Pernambuco, Brasil.

Matos, A. M. R. (2012). SPECTRUM: uma norma de gestão de coleções para os museus portugueses. (doctoral thesis). Faculdade de Letras da Universidade do Porto, Portugal. Retrieved from: http://repositorioaberto.up.pt/handle/10216/67304.

Meskell, L. (2005). Archaeologies of Materiality. Oxford: Blackwell Publishing.

Mesquita, S. (2012). Conservação preventiva e reservas técnicas: ainda um desafio para as instituições. In: Silva, R.R.G. (Org.), Preservação documental: uma mensagem para o futuro (p. 67-77). Salvador, Brasil: EDUFBA.

Michalski, S. (2004). Conservação e preservação do acervo. In: UNESCO/ICOM. Como gerir um museu: manual prático. França: ICOM. Retrieved from: http://unesdoc.unesco.org/images/0018/001847/184713por.pdf.

Michalski, S. (2013). Agent of deterioration: Incorrect Relative Humidity. Canadá: Canadian Conservation Institute. Online. Retrieved from: http://www.cci-icc.gc.ca/resources-ressources/agentsofdeteriorationagentsdedeterioration/chap 10-eng.aspx. 
Milheira, R. G., Peixoto, L. C., Caldas, K. V., \& Azevedo, P. A. S. (2017). Manual de gestão da reserva técnica sob a salvaguarda do LEPAARQ - UFPEL. Revista Arqueologia Pública, v. 11(2), p. 25-42. Doi:10.20396/rap.v11i2.8651103.

Milheira, R. G., Caldas, K. V., Santos, V. C. B., Peixoto, L. C., Azevedo, P. A. S., \& Barros, J. S. Conservação preventiva em acervos arqueológicos: o desafio na reserva técnica do LEPAARQ/ UFPEL. Revista Patrimonium, Belo Horizonte, v. 1(2), p. 15-18.

Monteiro, J. (2014). Documentação em museus e objeto-documento: sobre noções e práticas. (master's thesis). Escola de Comunicações e Artes da Universidade de São Paulo, São Paulo, Brasil.

Pereira, D. (2017). Extroversão do Patrimônio Arqueológico Salvaguardado: A reserva técnica do laboratório de arqueologia Peter Hilbert. Revista de Arqueologia Pública, v.11(2) p. 66-82. Doi: 10.20396/rap.v11i2.8650061.

Poccolo, R. \& Tinoco, J. (2009). Sobre os objetos e objetivos da conservação: o caso das instalações elétricas da Basílica da Penha no Recife. Textos para Discussão - Série 2: Gestão de Restauro. Olinda, Brasil: CECI.

Price, N. S. (1986). Scavo e Conservazione. La Conservazione sullo Scavo Archeologico. Roma: ICCROM.

Sallés, J. M. \& Ribeiro, D. L. (2011). Consideraciones sobre el papel del conservador en las excavaciones arqueológicas. Resúmenes I Congresso internacional e Arqueologia de La cuenca Del prata. Buenos Aires: Secretaria de cultura.

Sallés, J. M., Tocchetto, F., Dode, S. S., Souza, T. S., Silva, F. B. D.; Dutra, M. R. R., ... Domingues, B. S. (2017). Protocolo de ingresso de acervos arqueológicos em Instituições de Guarda e Pesquisa: uma proposta do Lâmina/UFPel e do Museu de Porto Alegre Joaquim Felizardo - RS. Revista de Arqueologia Pública, 11 (2). p. 06-24.

Santos, C. R. B. (2017). Conservação preventiva e gestão de vestígios arqueológicos de natureza orgânica da Reserva Técnica de materiais de natureza orgânica (RETEC-ORG). Estudo de caso: coleção de remanescentes humanos do sítio Alcobaça - Buíque - PE. (undergraduate thesis). Universidade Federal de Pernambuco, Brasil.

Santos, M. O. \& Souza, P. (2004). Parâmetros para a Conservação de Acervo. Museologia. Roteiros práticos (v. 5). São Paulo: Editora da Universidade de São Paulo.

Strang, T. \& Kigawa, R. (2013). Agent of Deterioration: Combatting Pests of Cultural Property. Canadá: Canadian Conservation Institute. Retrieved from: http://www.cci-icc.gc.ca/resourcesressources/agentsofdeterioration-agentsdedeterioration?chap06eng.asppx.

Souza, L. A. C. S., Rosado, A. \& Froner, Y-A. (2008a). Tópicos em Conservação Preventiva 1: Roteiro de Avaliação e Diagnóstico em Conservação Preventiva. Belo Horizonte: LACICOR-EBA-UFMG, IPHAN.

Vasconcelos, M. L. C. \& Alcântara, T. M. (2017). Com quantas caixas se faz uma Reserva Técnica? Um relato de experiência sobre a Gestão dos Acervos Arqueológicos no MAE/ UFBA. Revista de Arqueologia Pública, 11(2). p. 153-165.

Wichers, C. A. M. (2014). Dois enquadramentos, um mesmo problema: os desafios da relação entre museus, sociedade e patrimônio arqueológico. Revista de Arqueologia, v.27(1), p. 16-39. 